\title{
The Belt and Road Economic Zone cross-border e-commerce development model research
}

\author{
Zhang Wei ${ }^{1}$ \\ ${ }^{1}$ Xi’an International University, Xi’an, Shaanxi, China, 710077
}

\begin{abstract}
Keywords: Belt and Road Initiative Economic Zone Development Model of cross-border E-commerce
\end{abstract}

\begin{abstract}
The Belt and Road economic development strategy is the Secretary Xi Jinping led the party and state leaders, now the face of the world and China economic development situation, the national development plan new strategy, in order to improve the China economy and the world economy and the new development road, and carry out new economic cooperation along the Silk Road countries, thus achieving economic balance the eastern and Western world. The cross-border electricity supplier for the practice of regional integration and development to expand the new development path, based on the The Belt and Road district economic development model of cross-border e-commerce in-depth research, analysis of cross-border e-commerce based on Belt and Road Initiative "development foundation, China's cross-border e-commerce development present situation, The Belt and Road regional economic development model of cross-border e-commerce in order to achieve better exploration, promote the development of China's e-commerce economy a road in the area of economic development background.
\end{abstract}

\section{Preface}

"Belt and Road Initiative" is China's strategy for the development of national important next phase, advocated a greater degree of China with The Belt and Road along the country to carry out economic cooperation, economic development strategy and regional economic integration is an important part of the economy, through the expansion of open cooperation is conducive to national the improvement of the economic level, create a stable diplomatic cooperation environment, to promote the economic development of the country and the area along the increase. Bring the enormous influence of new economic development strategy for the economic development of our country, provides strategic guidance and support structure for China economic globalization strategy, the Internet information technology, electronic commerce has changed the economic model to support the social production and people's life mode, the development of global economic integration, brings great development opportunities for the economic development of countries, China advocates The Belt and Road economic development strategy development concept of global economic integration, the development model of cross-border e-commerce will be able to cross domain geographical limitations, to achieve interoperability of international network economy and commodity sales and service, with the development of regional economy in different countries and cultural background and economic development the structure there is a big difference, the cross domain of regional culture, political factors and economic structure of the new The model of commodity trading activities provides a new way to promote the economic development of the cooperative areas[1].

\section{Cross-border e-commerce based on the development of basic The Belt and Road "}

Covers The Belt and Road economic development strategy relates to the world's more than 60 countries and regions, these countries and regions generally for the developing economies and emerging economies, has great potential in economic development, more than half of the world to the total population, due to the economic structure has a certain similarity, and the continuous increase the population flow between different regions, promote economic activity between 
countries are becoming increasingly frequent, in Chinese and East Asia, North America, South America and other countries trade growth trend gradually slowed down the situation, The Belt and Road regional economic development to expand a new trade space for Chinese. Trade in agricultural products, commodities, crude oil and other products have been frequent. At the same time, domestic consumers have increased awareness of products in Central Asia, Western Asia, Russia and other countries.

The development of electronic and information technology laid the foundation for the development of mature for the development of e-commerce, cross-border e-commerce also cater to the needs of the public consumption and application development, more and more countries to participate in cross-border economic development models. The progress of social economy, the quality of life of our people demand is also rising, the market consumption potential have been found, China has become the largest imports of cross-border e-commerce, with the continuous economic development, China's cross-border consumption demand will continue to rise. At the same time, the level of development of cross-border e-commerce The Belt and Road economic region is lagging behind, foreign trade enterprises and foreign trade activities are still using the traditional mode of trade development, according to the lack of service platform for cross-border e-commerce services to the part of the region, limiting the development of regional economic network[2].

Since China's reform and opening up, agricultural economy, forestry, animal husbandry and fishery economy economic economy has been rapid development, to achieve industrial economic development is behind many industrial products as economic support, China's agricultural products planting, aquaculture and forestry animal husbandry product development has formed a complete industrial chain at the same time, China's social life to meet the demand for products, also produced a large supply of products, will be able to carry more consumer demand, cross-border e-commerce to expand the sales of product sales radius, networked product promotion and sales model to Chinese products out of the country and provide a more convenient way. At the same time The Belt and Road economic zone outside the country, will also be national and regional advantage products, through e-commerce channels into the Chinese consumer market, the Central Asian countries of high-quality agricultural products, Russian dairy products, seafood in Western Europe and so on, are in the world market in the competitive strength of the product quality, product radiation the scope of cross domain border, to the world people's life more abundant, also provide the impetus for the national industrial economic development.

Concept of consumption and consumer behavior is the foundation to ensure the development of the market economy, the progress of social economy, the demand of people for life is not only limited to the subsistence level, diversified and personalized consumption concept has become the trend of development of our society, people from the quality, pay attention to the quality of products, pay attention to the product brand culture, pay attention to the product of geographical and cultural background so, the focus is more diverse, the consumption level also gradually improve, expand more profit space for the development of the market economy. At the same time, continuous integration and exchange of world culture, the non economic elements of ethnic customs, religious beliefs, social culture and differentiated to obtain a more recognized broad space between people, to different cultural backgrounds based on their consumption behavior and consumption idea to give more respect, cross-border e-commerce can provide the mode of economic development the more differentiated product choices for consumers, we can also cater to the transformation of consumption concept, and timely adjustment of product supply direction, help to promote the development of the electronic commerce[3].

\section{The analysis of the development of cross-border e-commerce in China}

The development of China's economy is to realize the nature of people and improve the level of the source of consumption, nearly six hundred million of the middle class with strong consumption ability, on the basis of the traditional consumption mode of e-commerce, cross-border e-commerce for the people at home will be better quality of origin foreign goods to the country, into the 
grass-roots people's life. Tmall international is currently the main platform of China's cross-border e-commerce transactions, according to the 2016 group reported a resident users of cross-border e-commerce platform in Tmall international annual consumption of 2016 to 40 million, and the application of population is growing daily, with young population rising disposable income, China's cross-border e-commerce consumption will continue to grow. For The Belt and Road economic development strategy, will bring great development opportunity for the development of cross-border e-commerce, the Alibaba group has the layout of e-commerce in the country such as Malaysia, which lays a foundation for the further development of cross-border e-commerce. The continuous development of e-commerce industry, its economic development model and service model will realize from "quantity" to "quality" change process, and strive to create an all-weather service platform.

With the rapid development of cross-border e-commerce at the same time, but also reflects the characteristics of regional economic development is not balanced, and the traditional mode of economic development is similar, there is a big relationship based e-business development level and development level of regional economy, regional economic development a good foundation, to provide high-quality products for e-commerce platform to achieve efficient service advantage, but if the lack of foundation of regional economic development, not only difficult to guarantee the quality of products, the service advantage will be because of transportation, commodity circulation and other issues significantly weaken. At present, the main regional cooperation in cross-border e-commerce in China to Southeast Asia, Oceania, North America and parts of Europe, but for The Belt and Road economic regions along the country, there is a greater cooperation and development space, restricted economic development is not balanced in different areas, cross-border cooperation and expand is affected to a certain extent.

Logistics is an important factor to ensure the development of cross-border electricity supplier chain, the domestic electronic commerce in China with the rapid development of domestic transportation infrastructure improvement has a direct impact, also need to cross-border e-commerce logistics system as the basis for development, but many countries in The Belt and Road economic zone are the transportation infrastructure problem area the way of economic development strategy of our country is at the initial stage of construction, for the construction of other state support is still in the initial stage, the problems of circulation and service system construction practice to transfer economic area high logistics costs, long products, have become an important problem to restrict the cross-border electricity supplier in China The Belt and Road economic development zone.

\section{The Belt and Road regional economic development model of cross-border E-commerce}

The formulation and implementation of The Belt and Road "economic development strategy, more and more countries and regions to see the comprehensive strength of China economy, and the huge influence of Chinese economy on world economic development. The electronic commerce mode of our country economy has become an important force in China's economic development, the development of cross-border electricity supplier will The Belt and Road Economic Zone economic development plays an important role in promoting. In order to promote the development of cross-border e-commerce in The Belt and Road Economic Zone shall, from the national level, enhance the economic and regional countries in communication and cooperation, strengthen policy support for cross-border e-commerce construction, provide the basic guarantee for the development of cross-border e-commerce. Cross-border electronic commerce involves the scope of business, product display problems, problems, problems, foreign exchange trading credit protection issues should be given full consideration in the construction of policy system, cooperation between the two sides according to the need of special service form of electronic commerce to set up a special organization, in its response to the development process involved in the service and business conduct giving help, coordination and supervision, and set up the management responsibility system, guiding the communication mechanism, improve joint meeting mechanism and monitoring management mechanism according to the actual needs of the work, the use of policy system as the 
guarantee for the development of cross-border e-commerce, and will link government, market and operation of all aspects of the factors of development of cross-border e-commerce security can be sustained, stable and healthy growth.

Enterprise is the main cross-border e-commerce business, cross-border e-commerce enterprises need according to the needs of the market oriented, with its own features and advantages for the development of regional product features, product market as a foundation, gradually build independent product brand and service quality, through the improvement of product quality and product promotion, gradually expanding the brand of social influence and credibility, the development demand of cross-border electricity supplier product differentiation, so that products can get more market space in the cross-border electronic business platform, help to promote the enterprise market achieve economic benefits[4].

The Belt and Road economic zone covers most of China's provinces and regions in our country, under its economic radiation driven, the local government should encourage local independent construction enterprises to carry out cross-border e-commerce platform, regional advantages of electronic commerce in China is concentrated in the eastern region, the development has a certain advantage, but in the western region it is difficult to focus on the local characteristics, the e-commerce platform reflects different areas should be based on their own development advantages as the basis, the establishment of cross-border electronic business service platform with its own development needs. Taking Xinjiang area as an example, Xinjiang is the origin of our country large quantities of tomatoes, carrots, celery, fruits and other agricultural products, tomato yield occupy $1 / 4$ of the world's total output, and $98 \%$ of these tomatoes are exported to foreign countries, the local government will be able to rely on the macroeconomic advantages, the construction of local cross-border e-commerce platform, to promote the better development of the local economy and industrial economy.

Internet banking has become a new financial service mode is widely popular in the international community, should be based on the strategic development The Belt and Road Belt and Road Initiative economic region, improve inter regional, National Internet financial service system, commodity trading involves the product value and capital exchange, construction of Internet financial development needs to expand cross-border payment platform, ensure the convenience the safety of cross-border payments. At the same time, regional credit reporting system should be established to provide protection for more diversified cross-border financial services activities[5].

\section{Conclusion}

Cross-border e-commerce is an important component of the future development of the world economy, The Belt and Road economic region has become a major area of the world economic development in the future, it brings the opportunities of economic development based on regional, local government should be based on their own business development advantages, the depth distribution of advance in economic development, at the same time, countries and regions should be strengthened security policy, national and regional autonomy encourages the construction of cross-border e-commerce platform, related departments should improve the financial service system of the world, through the joint efforts of a variety of ways, to provide momentum for the development of cross-border electricity supplier.

\section{References}

[1]Wang J J, Jia-Lin D U. Exploring the Cross-border E-commerce Development Model in the Belt and Road Economic Regions[J]. China Business \& Market, 2016.

[2]Zhang G. Research on Cultivating Linguistic Skills of Cross-border E-commerce English Talents under the Background of qOne Belt and One Roadq[C]// International Conference on Social Science, Education and Humanities Research. 2016.

[3]Sun X, Gao X, Meng Z. The Analysis of Jilin Province “One Belt and One Road” Cross-— 
Border E-commerce Economic Cooperation Status[J]. Journal of Industrial Technological \& Economics, 2016.

[4]Liu H M, Fang C L, Ren Y F. Logistics industry and cross-border electric business of Sino-Kazakhstan cooperation demonstration zone in Silk Road Economic Belt[J]. Arid Land Geography, 2016.

[5]Yong-Hong D U. Research on the Development Strategy of Cross-border E-commerce Based on the Background of “The Belt and Road” [J]. Reform of Economic System, 2016. 